\title{
Synthesis of the C1-C52 Fragment of Amphidinol 3, Featuring a $\beta$-Alkoxy Alkyllithium Addition Reaction
}

\author{
John R. Huckins, Javier de Vicente, and Scott D. Rychnovsky ${ }^{*}$ \\ Department of Chemistry, 1102 Natural Sciences II, University of California, Irvine, Irvine, California, \\ 92697-2025.
}

\begin{abstract}
An advanced intermediate for the synthesis of amphidinol 3 has been prepared. A cross-metathesis reaction was used to couple the $\mathrm{C} 1-\mathrm{C} 12$ and $\mathrm{C} 13-\mathrm{C} 26$ segments. An unusual $\beta$-alkoxy alkyllithium reagent was generated from this segment and added to a Weinreb amide to assemble the C1-C52 section of amphidinol 3. These compounds represent some of the most advanced intermediates reported to date for the synthesis of amphidinol 3.
\end{abstract}

The amphidinols are a fascinating group of metabolites isolated from the marine dinoflagellates Amphidinium klebsii and Amphidinium carterae. ${ }^{1}$ Amphidinol 3 (1) exhibits potent hemolytic activity against human erythrocytes as well as antifungal activity against Aspergillus niger. ${ }^{1}$ A variety of amphidinols have been reported, along with the structurally similar compounds luteophanol A and lingshuiol A and B. ${ }^{2}$ Common structural features of these natural products are two highly substituted tetrahydropyran (THP) rings, a long, irregular polyol domain, and a skipped polyene chain. Among this family of natural products, only the configuration of amphidinol 3 has been assigned. The absolute stereochemistry of amphidinol 3 was elucidated by Murata and coworkers using a new and powerful $J$-based NMR spectroscopic technique.

3 Amphidinol 3 has emerged as an important synthetic target, and a number of groups, including our own, ${ }^{4}$ have reported progress towards its synthesis. ${ }^{5}$ Herein, we describe the synthesis of the fully protected $\mathrm{C} 1-\mathrm{C} 52$ fragment.

Our retrosynthetic analysis for amphidinol 3 is illustrated in Figure 1. The three components are a bis-tetrahydropyran $\mathbf{2}$, a polyene sulfone $\mathbf{3}$, and the protected polyol $\mathbf{4}$. The bis-THP $\mathbf{2}$ is similar to and derived from an intermediate we have previously reported. ${ }^{4}$ Synthesis and coupling reactions with the polyene sulfone have also been described. ${ }^{4 a}$ The synthesis of protected polyol phenylthio ether $\mathbf{4}$ and strategies for its coupling will be the focus of this discussion.

The key coupling reaction between phenylthio ether $\mathbf{4}$ and Weinreb amide $\mathbf{2}$ was envisioned as an addition of the alkyllithium reagent derived from $\mathbf{4}$ to the amide $\mathbf{2}$. The resulting $\beta$ hydroxy ketone would be suitable for stereoselective reduction. Elimination of the $\mathrm{C} 25$ oxygen would be avoided by masking it as a lithium alkoxide. Such $\beta$-alkoxy alkyllithium reagents are known. They have been prepared by mercury-lithium exchange, ${ }^{6}$ reductive lithiation of chlorohydrins, ${ }^{7}$ reductive lithiation of oxiranes, ${ }^{8}$ and from $\beta$-hydroxy phenylthio ethers. ${ }^{9}$ Several reasonably complex $\beta$-alkoxy alkyllithium reagents have been prepared by reduction of oxiranes, ${ }^{10}$ but these reagents have not been used to couple complex fragments. 
A model coupling reaction was investigated as outlined in Scheme 1. The $\beta$-hydroxy phenyl sulfide 5 was prepared and deprotonated with $n$-BuLi. Addition of lithium di-tertbutylbiphenylide $(\mathrm{LiDBB})^{11}$ at low temperature generated the $\beta$-alkoxy alkyllithium $\mathbf{6}$. Subsequent addition of the Weinreb amide $\mathbf{7}$ produced the desired $\beta$-hydroxy ketone $\mathbf{8}$ in 69\% yield. The encouraging outcome of this model study emboldened us to move forward with the amphidinol 3 synthesis.

The synthesis of Weinreb amide 2 from the bis-THP intermediate $4 \mathrm{a} \mathbf{9}$ is presented in Scheme 2. Low temperature TBAF treatment selectively removed the primary TBS group, and oxidation gave the expected C31 aldehyde. Additions to this aldehyde were very problematic, perhaps because of the steric crowding. A 2-propenyllithium addition failed and the corresponding Grignard addition gave only trace quantities of the expected allylic alcohol products. Finally, a Nozaki-Hiyama-Kishi reaction ${ }^{12}$ with 2-bromopropene led to the desired alcohol diastereomers in good yield, and acylation gave ester 10. Ireland-ester Claisen rearrangement ${ }^{13}$ using Nakai's in situ method for generating the silyl ketene acetal ${ }^{14}$ produced the expected unsaturated silyl ester in good yield. Hydrolysis of the silyl ester and coupling with $N$-methoxy- $N$-methylamine produced the Weinreb amide $\mathbf{2}$ as a single alkene isomer.

The C14-C26 segment of amphidinol 3 was prepared from (S)-glyceraldehyde acetonide (11) as illustrated in Scheme 3. The syn crotyl adduct 12 was prepared by Roush's procedure. ${ }^{15} \mathrm{~A}$ set of standard transformations led to the phenyltetrazole sulfone 13, which was coupled with aldehyde 14 using the Julia-Kocienski method ${ }^{16}$ to produce the $E$-alkene $\mathbf{1 5}$ as a single isomer. The reaction was optimized (KHMDS, DME, Barbier conditions) to produce high $E / Z$ selectivity to avoid subsequent problematic separations of alkene or diol diastereomers. Sharpless asymmetric dihydroxylation led to a single diastereomer by ${ }^{1} \mathrm{H}$ NMR analysis. ${ }^{17}$ Protection of the diol, selective deprotection of the primary TBS ether ${ }^{18}$ and oxidation delivered the aldehyde 16 in excellent overall yield. The enone 17 was prepared by addition of vinylmagnesium bromide to the aldehyde and oxidation. Both 16 and 17 were plausible intermediates for the C14-C26 segment of amphidinol 3.

Initially we planned to add a $\mathrm{C} 1-\mathrm{C} 13$ organozinc reagent to aldehyde $\mathbf{1 6}$ to assemble the $\mathrm{C} 1$ $\mathrm{C} 26$ fragment. ${ }^{19}$ We prepared the protected polyol 18 using a modification of Cossy's elegant metathesis route (Scheme 4). ${ }^{5 a, 20}$ Unfortunately, numerous attempts to prepare a dialkylzinc reagent from 18 failed; the hydroboration was successful but the transmetalation was not. Ultimately the successful coupling strategy used a cross-metathesis reaction, Scheme $4 .^{21}$ Enone 17 was combined with triene 18 in a 1:1 molar ratio and exposed to the Grubbs-Hoveyda catalyst $(10 \mathrm{~mol} \%){ }^{22}$ The reaction produced enone 19 in $69 \%$ yield. Stereoselective reduction of the $\mathrm{C} 14$ ketone was accomplished using the CBS reagent ${ }^{23}$ to deliver the required C14- $R$ diastereomer with $17: 1$ selectivity in $92 \%$ yield. Following Roush's precedent, $5 \mathrm{~b}$ hydroxyldirected reduction using Noyori's catalyst ${ }^{24}$, saturated the C12-C13 alkene and produced the C1-C26 segment 20 after protection. The proposed dialkylzinc strategy would have required fewer steps, but the metathesis route was very effective.

To set up the coupling between the bis-THP fragment and the C1-C26 polyol segment, the phenyl sulfide needed to be introduced and the protecting groups adjusted. Selective hydrolysis of the acetonide was accomplished by enol ether formation and hydrolysis. ${ }^{25}$ Removal of the benzyl ether, epoxide formation, SEM protection and treatment with thiophenol and base delivered the desired C1-C26 synthon $\mathbf{4}$ in good overall yield.

The final segment coupling between protected polyol 4 and bis-THP 2 is illustrated in Scheme 4. Deprotonation of the $\mathrm{C} 25$ alcohol with $n$-BuLi, followed by reductive lithiation with LiDBB generated the $\beta$-alkoxy alkyllithium 23. The bis-THP Weinreb amide 2 was added to the alkyllithium solution in THF at $-78^{\circ} \mathrm{C}$, and the reaction was allowed to proceed for $21 \mathrm{~h}$ at 
that temperature. The $\beta$-hydroxy ketone $\mathbf{2 4}$ was isolated in $59 \%$ yield. A four-fold excess of the $\mathrm{C} 1-\mathrm{C} 26$ segment was used in the coupling, but this ratio was largely dictated by the relative abundance of the two coupling partners. Model studies to prepare ketone 8 used a three-fold excess, but neither of these ratios were optimized. Synthesis of the C1-C52 segment of amphidinol 3 was completed by hydroxyl-directed reduction of the $\mathrm{C} 27$ ketone using Prasad's conditions, ${ }^{26}$ followed by alcohol protection to produce the amphidinol 3 intermediate 25 .

We have developed an efficient construction of an advanced intermediate for the synthesis of amphidinol 3. The route features segment coupling reactions using a cross-metathesis and a $\beta$-alkoxy alkyllithium addition to a Weinreb amide. These validated coupling strategies will undoubtedly be useful in the synthesis of other complex natural products.

\section{Supporting Information Available}

Refer to Web version on PubMed Central for supplementary material.

\section{Acknowledgements}

This work was supported by the National Institute of General Medical Sciences (GM-65338) and by a generous donation from the Schering Plough Research Institute. J.d.V. acknowledges the Spanish Ministry of Education and Science for a postdoctoral fellowship.

\section{References}

1. Murata M, Matsuoka S, Matsumori N, Paul GK, Tachibana K. J Am Chem Soc 1999;121:870-871.

2. a Paul GK, Matsumori N, Murata M, Tachibana K. Tetrahedron Lett 1995;36:6279-6282. b Satake M, Murata M, Yasumoto T, Fujita T, Naoki H. J Am Chem Soc 1991;113:9859-9861. c Houdai T, Matsuoka S, Murata M, Satake M, Ota S, Oshima Y, Rhodes LL. Tetrahedron 2001;57:5551-5555. d Paul GK, Matsumori N, Konoki K, Murata M, Tachibana K. J Mar Biotechnol 1997;5:124-128. e Echigoya R, Rhodes L, Oshima Y, Satake M. Harmful Algae 2005;4:383-389. f Doi Y, Ishibshi M, Nakamichi H, Kosaka T, Ishikawa T, Kobayashi Ji. J Org Chem 1997;62:3820-3823. g Huang XC, Zhao D, Guo YW, Wu HM, Trivellone E, Cimino G. Tetrahedron Lett 2004;45:5501-5504.

3. Matsumori N, Kaneno D, Murata M, Nakamura H, Tachibana K. J Org Chem 1999;64:866-876. [PubMed: 11674159]

4. a de Vicente J, Huckins JR, Rychnovsky SD. Angew Chem, Int Ed 2006;45:7258-7262. b De Vicente J, Betzemeier B, Rychnovsky SD. Org Lett 2005;7:1853-1856. [PubMed: 15844923]

5. a BouzBouz S, Cossy J. Org Lett 2001;3:1451-1454. [PubMed: 11388839] b Flamme EM, Roush WR. Org Lett 2005;7:1411-1414. [PubMed: 15787519] c Hicks JD, Flamme EM, Roush WR. Org Lett 2005;7:5509-5512. [PubMed: 16288543] c Chang SK, Paquette LA. Synlett 2005:2915-2918. d Paquette LA, Chang SK. Org Lett 2005;7:3111-3114. [PubMed: 15987218] e Dubost C, Marko IE, Bryans J. Tetrahedron Lett 2005;46:4005-4009. f Bedore MW, Chang SK, Paquette LA. Org Lett 2007;9:513-516. [PubMed: 17249800]

6. a Barluenga J, Fananas FJ, Yus M. J Org Chem 1979;44:4798-4801. b Barluenga J, Fananas FJ, Yus M. J Org Chem 1981;46:1281-1283.

7. a Barluenga J, Florez J, Yus M. J Chem Soc, Chem Commun 1982:1153-1154. b Barluenga J, Florez J, Yus M. J Chem Soc, Perkin 1 1983:3019-3026. c Najera C, Yus M, Seebach D. Helv Chim Acta 1984;67:289-300.

8. a Bartmann E. Angew Chem, Int Ed 1986;25:653-655. b Cohen T, Jeong IH, Mudryk B, Bhupathy M, Awad MMA. J Org Chem 1990;55:1528-1536. c Bachki A, Foubelo F, Yus M. Tetrahedron: Asymmetry 1996;7:2997-3008.

9. a Foubelo F, Gutierrez A, Yus M. Tetrahedron Lett 1997;38:4837-4840. b Foubelo F, Gutierrez A, Yus M. Synthesis 1999:503-514.

10. a Soler T, Bachki A, Falvello LR, Foubelo F, Yus M. Tetrahedron: Asymmetry 2000;11:493-517. b Falvello LR, Foubelo F, Soler T, Yus M. Tetrahedron: Asymmetry 2000;11:2063-2066. c Yus M, Soler T, Foubelo F. Tetrahedron: Asymmetry 2001;12:801-810. 
11. Freeman PK, Hutchinson LL. J Org Chem 1980;45:1924-1930.

12. Wessjohann LA, Scheid G. Synthesis 1999:1-36.

13. Ireland RE, Mueller RH, Willard AK. J Am Chem Soc 1976;98:2868-2877.

14. Kobayashi M, Masumoto K, Nakai Ei, Nakai T. Tetrahedron Lett 1996;37:3005-3008.

15. Roush WR, Adam MA, Walts AE, Harris DJ. J Am Chem Soc 1986;108:3422-3434.

16. a Baudin JB, Hareau G, Julia SA, Ruel O. Tetrahedron Lett 1991;32:1175-1178. b Blakemore PR, Cole WJ, Kocienski PJ, Morley A. Synlett 1998:26-28. c Blakemore PR. J Chem Soc, Perkin Trans 1 2002:2563-2585.

17. Kolb HC, Van Nieuwenhze MS, Sharpless KB. Chem Rev 1994;94:2483-2547.

18. Feixas J, Capdevila A, Guerrero A. Tetrahedron 1994;50:8539-8550.

19. a Pu L, Yu HB. Chem Rev 2001;101:757-824. [PubMed: 11712502] b Knochel P, Singer RD. Chem Rev 1993;93:2117-2188. c Lutz C, Knochel P. J Org Chem 1997;62:7895-7898.

20. Preparation of triene $\mathbf{1 8}$ is presented in the Supporting Information section.

21. Chatterjee AK, Choi TL, Sanders DP, Grubbs RH. J Am Chem Soc 2003;125:11360-11370. [PubMed: 16220959]

22. Kingsbury JS, Harrity JPA, Bonitatebus PJ, Hoveyda AM. J Am Chem Soc 1999;121:791-799.

23. a Corey EJ, Bakshi K, Shibata S. J Am Chem Soc 1987;109:5551-5553. b Corey EJ, Helal CJ. Angew Chem, Int Ed 1998;37:1986-2012.

24. Takaya H, Ohta T, Sayo N, Kumobayashi H, Akutagawa S, Inoue SI, Kasahara I, Noyori R. J Am Chem Soc 1987;109:1596-1597.

25. a Rychnovsky SD, Kim J. Tetrahedron Lett 1991;32:7219-7222. b Rychnovsky SD, Kim J. Tetrahedron Lett 1991;32:7223-7224. c Gassman PG, Burns SJ. J Org Chem 1988;53:5574-5576.

26. Chen KM, Hardtman GE, Prasad K, Repic O, Shapiro MJ. Tetrahedron Lett 1987;28:155-158. 

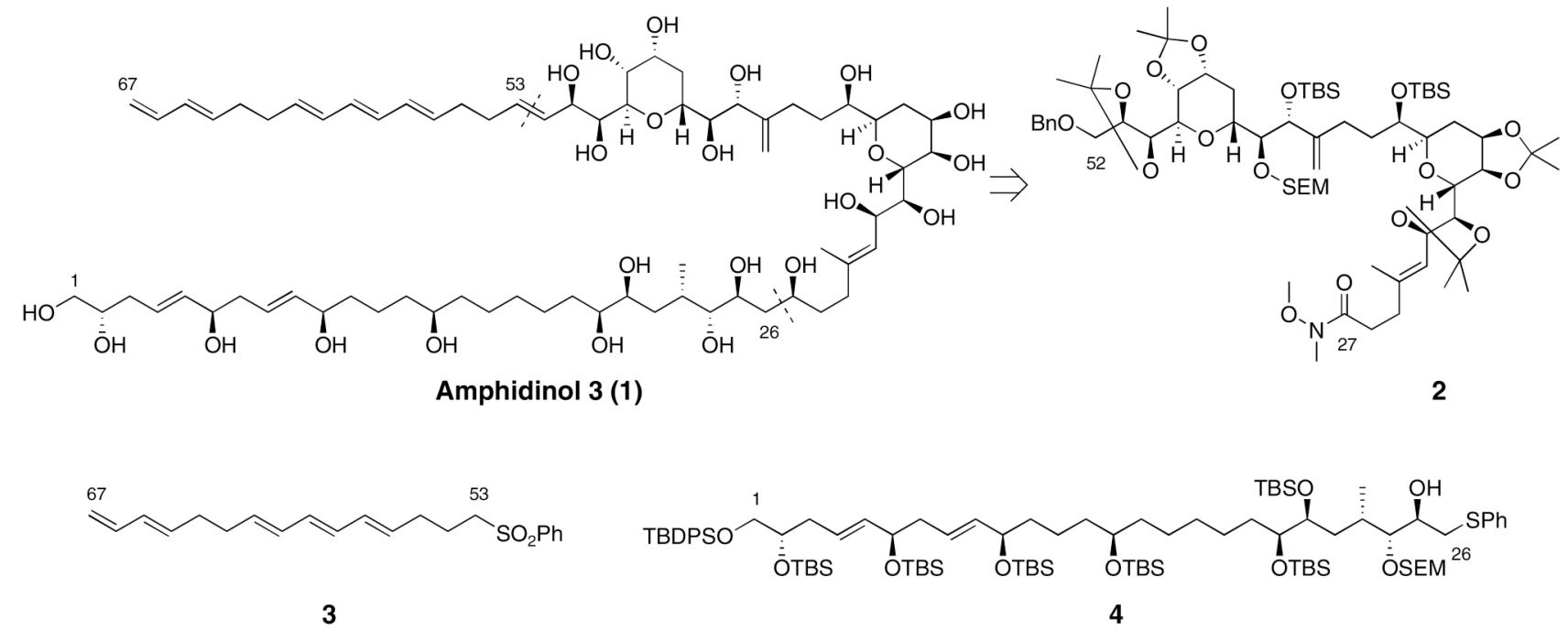

3

Figure 1.

Retrosynthetic analysis of amphidinol 3 

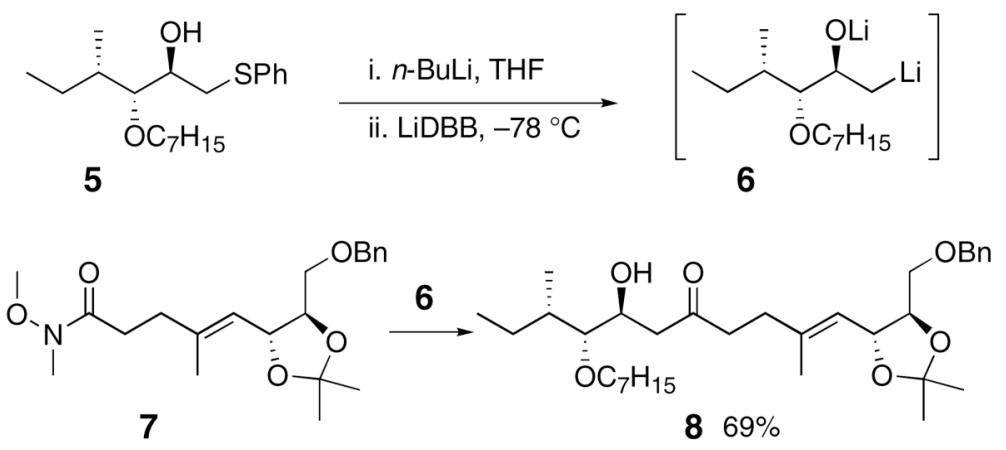

Scheme 1.

Model coupling of $\beta$-alkoxy alkyllithium 6 with Weinreb amide 7 


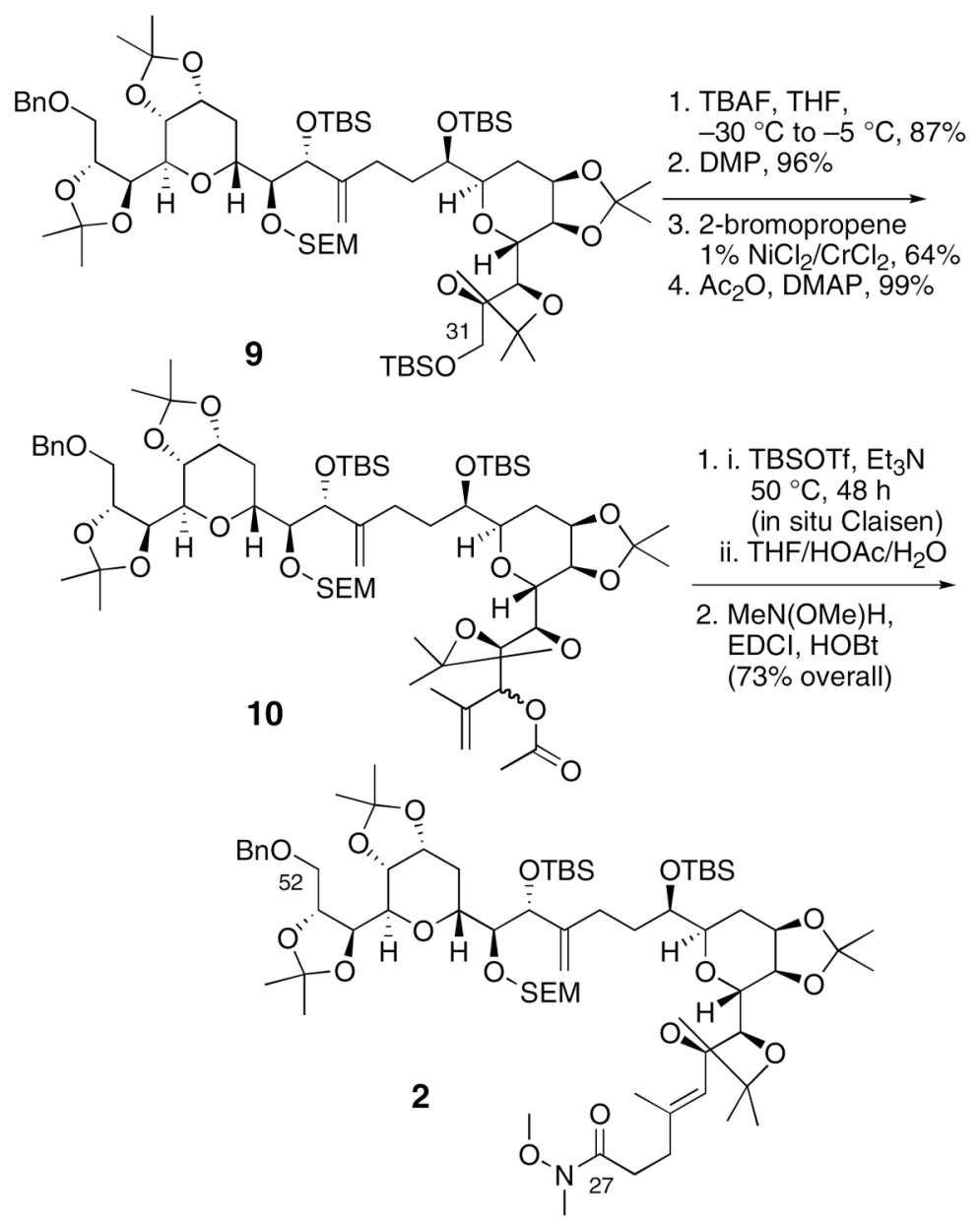

Scheme 2.

Synthesis of the C27-C52 Weinreb amide 2 

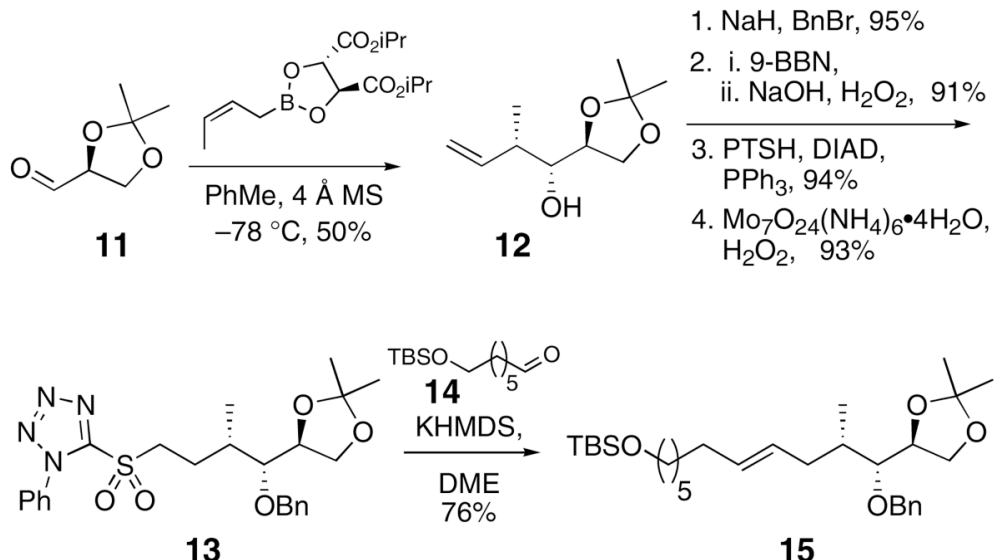

$$
\begin{aligned}
& \text { 1. Sharpless } \\
& \text { AD-mix- } \alpha, 98 \% \\
& \text { 2. TBSOTf, lutidine, } 98 \% \\
& \underset{\text { 3. } \mathrm{Al}_{2} \mathrm{O}_{3} \text {, hexanes, } 95 \%}{\text { 4. IBX, THF/DMSO, } 91 \%}
\end{aligned}
$$

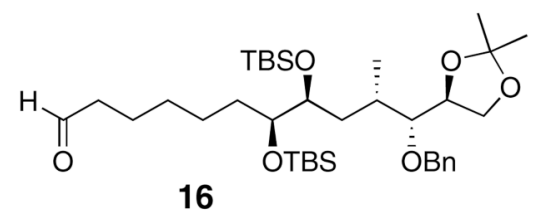

$$
\frac{\text { 1. } \mathrm{CH}_{2}=\mathrm{CHMgBr}, 93 \%}{\text { 2. IBX, } 87 \%}
$$

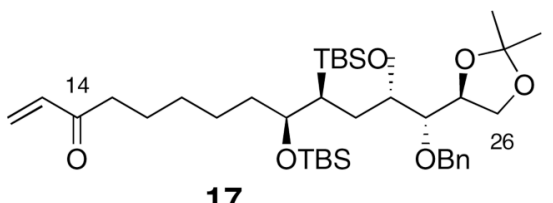

Scheme 3.

Synthesis of the C14-C26 aldehyde $\mathbf{1 6}$ and enone $\mathbf{1 7}$ 

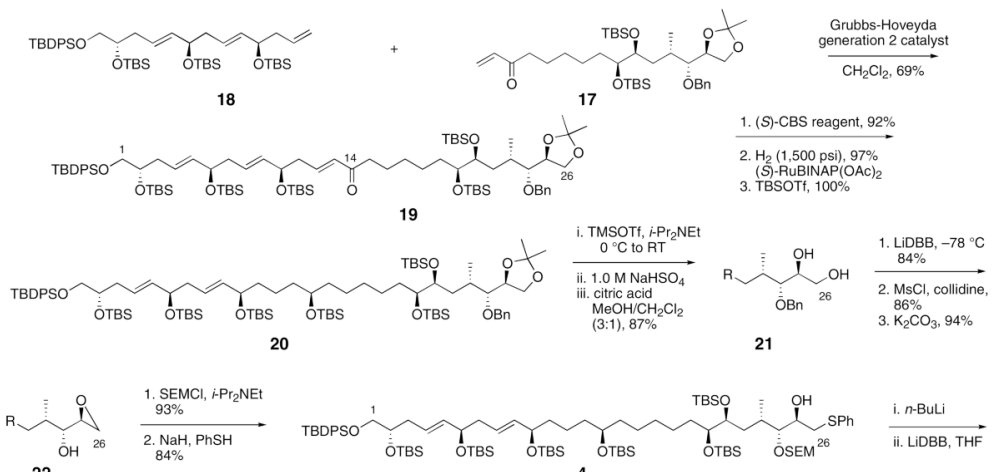

22

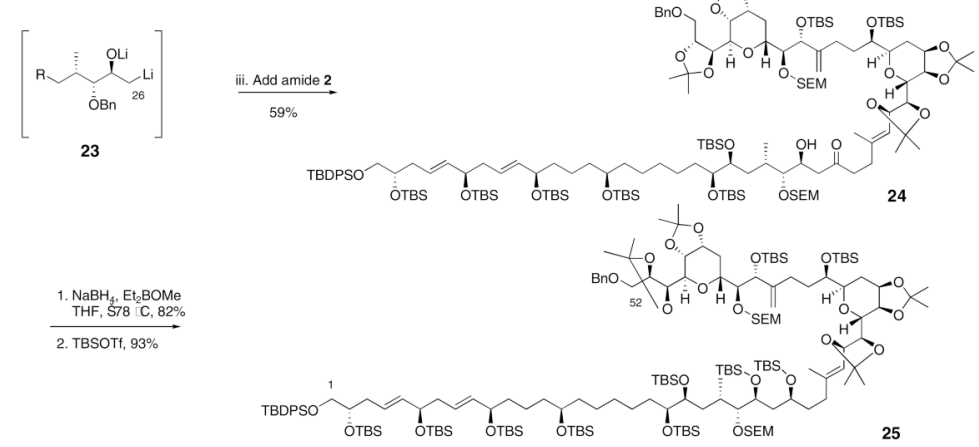

Scheme 4.

Coupling fragments to assemble the C1-C52 segment of amphidinol 3 